\title{
Nota à edição brasileira
}

Cláudia Damasceno Fonseca

\section{SciELO Books / SciELO Livros / SciELO Libros}

FONSECA, C.D. Nota à edição brasileira. In: Arraiais e vilas d'el rei: espaço e poder nas Minas setecentistas [online]. Belo Horizonte: Editora UFMG, 2011. Humanitas series, pp. 19-23. ISBN: 978-85-423-0307-0. https://doi.org/10.7476/9788542303070.0002.

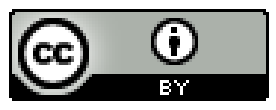

All the contents of this work, except where otherwise noted, is licensed under a Creative Commons Attribution 4.0 International license.

Todo o conteúdo deste trabalho, exceto quando houver ressalva, é publicado sob a licença Creative Commons Atribição 4.0.

Todo el contenido de esta obra, excepto donde se indique lo contrario, está bajo licencia de la licencia Creative Commons Reconocimento 4.0. 


\section{NOTA À EDIÇÃO BRASLLEIRA}

Todo trabalho de investigação, principalmente os mais longos e exigentes, está sempre relacionado, de alguma forma, ao itinerário pessoal do pesquisador. Um amigo anglófono me disse, um dia, que eu parecia ter uma ligação "orgânica" com o tema deste livro. Em princípio, a observação não me pareceu clara nem pertinente, mas com o tempo e o distanciamento, percebi que ele tinha razão: as origens mais remotas desta pesquisa têm qualquer coisa de "visceral". Ela nasceu de uma emoção, indefinível e profunda, que as paisagens urbanas mineiras sempre despertaram em mim, e que foi, em grande parte, responsável pela escolha da minha formação universitária inicial, de arquiteta e urbanista, e pela minha inclinação pelos trabalhos relacionados com inventários, restauração de monumentos e reabilitação de centros históricos. No entanto, este olhar técnico e pragmático sobre as cidades e sobre o seu passado não me satisfazia plenamente, sem que eu soubesse o porquê. Foi em 1992, em Paris, durante um curso de especialização em urbanismo, que encontrei a resposta, e que ocorreu o grande tournant no meu itinerário intelectual, profissional - e até mesmo pessoal -, na medida em que descobri o meu interesse pela geografia e história urbanas, pela iconografia e cartografia históricas, e, acima de tudo, a minha paixão pelo trabalho nos arquivos.

Desta "revelação" decorreu, inicialmente, o tema da dissertação de mestrado: a evolução urbana de Mariana, analisada dentro de uma abordagem ligada à geografia histórica e cultural. A procura de dados e, sobretudo, de documentos cartográficos sobre a cidade conduziu-me ao Arquivo Histórico Ultramarino de Lisboa, 
onde fiz, em 1994, meus primeiros mergulhos na documentação referente às Minas setecentistas - que foram igualmente determinantes para a escolha dos temas, problemáticas e recortes adotados no presente estudo. Ali, também tornou-se claro que o doutoramento deveria ser, sem sombra de dúvida, em História, e que a tese não deveria constituir um novo estudo monográfico, mas levar em consideração várias cidades, ou mesmo a rede urbana no seu conjunto, destacando a dimensão territorial do fenômeno da urbanização. De fato, o mestrado em Geografia havia alargado meus horizontes, aprofundando meu interesse por outras escalas da organização humana do espaço, bem como para as questões referentes à percepção e à representação dos territórios e das paisagens - as quais pude aprofundar durante o doutorado, através de leituras e de seminários.

Mais concretamente, este livro é o resultado da pesquisa realizada no âmbito do programa de doutoramento em História da École des Hautes Études en Sciences Sociales, iniciado em 1995 (sob a direção do saudoso Bernard Lepetit), e concluído em novembro de 2001, com orientação de Daniel Nordman e com o auxílio financeiro da CAPES.

A tese, originalmente intitulada Pouvoirs, villes et territoires: genese et représentations des espaces urbains dans le Minas Gerais (Brésil, XVIII - début du XIX siècle), foi publicada em 2003 pelo Centre Culturel Calouste Gulbenkian de Paris, numa versão ligeiramente condensada e sob o título Des terres aux villes de l'or: pouvoirs et territoires urbains au Minas Gerais (Brésil, XVIII siècle) - menos genérico e mais atraente para o leitor francês, mas que não convinha à nova edição. Sobretudo a referência às "vilas (ou cidades) do ouro" me pareceu inadequada por ser facilmente associável à historiografia tradicional, a qual, como se sabe, atribuía um papel primordial à mineração na formação do espaço e da sociedade de Minas. Ora, os casos analisados neste trabalho corroboram a ideia, já defendida por alguns especialistas, de que a agricultura e o comércio foram tão ou mais importantes (em determinados casos) que a extração aurífera no processo de gênese e desenvolvimento dos núcleos e da rede urbana. Ao se escolher o título Arraiais e vilas d'el rei, procurou-se enfatizar a condição colonial dos núcleos em questão, bem como o enfoque dado às relações entre poder (ou "poderes") e espaço (nas suas diversas dimensões e escalas). 
O processo de formatação do texto da presente edição foi bastante longo e laborioso, embora a tradução parcial efetuada por Maria Juliana Gambogi Teixeira tenha constituído um ótimo - e imprescindível - ponto de partida. Além do novo título, fui levada a introduzir outras modificações no texto, embora minha determinação inicial fosse de publicar uma tradução ipsis litteris da edição francesa. De fato, decorridos já muitos anos desde a defesa da tese, acabei sucumbindo à tentação de modificar a versão original, introduzindo novos dados e nuanças que me pareceram pertinentes ou necessárias, não somente em função da distância crítica em relação ao trabalho e das pesquisas que efetuei nos últimos anos, mas também levando em conta alguns dos comentários, críticas e sugestões feitas nos pareceres dos membros da banca de doutorado, em discussões acadêmicas ou em resenhas diversas, publicadas dentro e fora do Brasil. ${ }^{1}$

$\mathrm{Na}$ maior parte dos capítulos, limitei-me a corrigir os erros identificados na versão francesa, além de acrescentar as citações originais de obras e de documentos. Algumas poucas páginas foram substancialmente modificadas; na maior parte dos casos, trata-se apenas de pequenas "incrustações" de notas ou de frases no corpo do texto. Algumas hipóteses e análises, que se encontravam fragmentadas em vários capítulos, foram reforçadas e desenvolvidas, seja num capítulo específico, seja na introdução ou na conclusão. Mas, mesmo com essas modificações, pode-se considerar que, tanto em termos de forma como de conteúdo, o texto da edição francesa foi, em grande parte, conservado.

No que diz respeito às citações de obra e documentos, cabe assinalar que a ortografia foi atualizada e padronizada (o mesmo procedimento foi adotado para os nomes próprios e topônimos mencionados no corpo do texto), e a pontuação corrigida quando necessário. Além disso, algumas das citações presentes na edição francesa foram aqui mais generosamente transcritas, dado o maior interesse que elas poderão despertar no público brasileiro ou lusófono. Inversamente, mas no mesmo espírito, suprimi algumas explicações, definições e contextualizações que me pareceram óbvias e desnecessárias aos novos leitores, mas conservei outras, na perspectiva - ou na esperança - de que este livro possa atingir um público mais amplo, e não somente aos especialistas da história colonial de Minas e do Brasil. A introdução do índice remissivo também poderá tornar o livro útil a um maior número de pessoas. 
Outras mudanças dizem respeito à bibliografia: na medida do possível, procurei atualizá-las, acrescentando ou modificando as referências às dissertações e teses que foram defendidas e/ ou publicadas (e às quais tive acesso) após a edição do Centre Calouste Gulbenkian. Por outro lado, não teria sido possível levar em conta tudo o que se publicou sobre Minas Gerais desde então: além da minha própria bibliografia referente aos temas aqui tratados, acrescentei somente algumas publicações concomitantes à edição francesa, além de referências a estudos importantes que conhecia somente através de citações e comentários de outros autores, por não ter podido consultá-los diretamente durante a elaboração da tese.

Quinze anos após o início desta pesquisa, e apesar de todas as suas lacunas e imperfeições, é chegada a hora de colocar o derradeiro ponto final, mas não sem antes deixar algumas palavras aos que me ajudaram neste longo percurso. Não creio que seja necessário repetir aqui todos os nomes citados na tese e na edição francesa: os membros da banca, professores e colegas da École des Hautes Études en Sciences Sociales e de outras instituições francesas, pesquisadores portugueses, brasileiros e brasilianistas, funcionários de arquivos e bibliotecas, além de outros, nem sempre mencionados explicitamente, que colaboraram de muitas maneiras e em etapas diversas deste trabalho, seja em Paris, em Lisboa, no Rio de Janeiro, em São Paulo, em Belo Horizonte, em Mariana ou ainda nas várias outras cidades mineiras em que pesquisei. Todos eles sabem da minha dívida e do meu reconhecimento.

Cabe, no entanto, uma menção especial ao meu orientador, Daniel Nordman, e aos que me apoiaram e contribuíram, de diferentes maneiras, para esta edição: Laura de Mello e Souza, Hannelore Russell-Wood, Kenneth Maxwell, Maria Fernanda Bicalho, Bruno Feitler, Renata Malcher de Araújo, Renato Pinto Venâncio, Júnia Ferreira Furtado, Neil Safier, Julianna Barroso Fontenelle, Roberto Borges Martins. Agradeço, ainda, ao Centre Culturel Calouste Gulbenkian, pela cessão dos direitos de tradução, à Luísa Braz de Oliveira e à Tipografia Braga, por terem disponibilizado os arquivos das imagens da primeira edição. Meus agradecimentos também aos meus principais interlocutores da Editora UFMG, à Heloisa Maria Murgel Starling e à tradutora Maria Juliana Gambogi Teixeira. 
Outras ajudas preciosas e indispensáveis vieram da minha prima Julianna e da wróžka Katarina Pikula, que, nos últimos meses deste trabalho de edição, me substituíram durante incontáveis horas na minha função de mãe. Agradeço, também, o constante apoio e incentivo dos meus familiares, no Brasil, e da belle-famille francesa. E, claro, reitero minha gratidão àqueles a quem dediquei a edição anterior: à minha tia Glei, falecida em 1999, a quem devo a minha primeira estada em Paris, e muito do que daí resultou; aos meus pais e ao meu marido Stéphane, que constituem minha maior "torcida" e meus apoios mais sólidos e incondicionais.

Por fim, como não poderia deixar de ser, dedico esta edição às minhas pequenas Irene e Alice, fontes cotidianas de surpresas e das minhas maiores alegrias. 


\title{
As notas a seguir correspondem a Nota à edição brasileira, originalmente reunidas ao final desse livro.
}

\author{
pp. 587
}

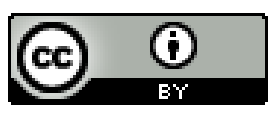

All the contents of this work, except where otherwise noted, is licensed under a Creative Commons Attribution 4.0 International license.

Todo o conteúdo deste trabalho, exceto quando houver ressalva, é publicado sob a licença Creative Commons Atribição 4.0.

Todo el contenido de esta obra, excepto donde se indique lo contrario, está bajo licencia de la licencia Creative Commons Reconocimento 4.0. 


\section{NO'TA À EDIÇÃO BRASILEIRA}

1 CALVO. Resenha de: FONSECA, Cláudia Damasceno; RUSSELL-WOOD. Resenha de: FONSECA, Cláudia Damasceno; HOORNAERT. Pour une méthodologie de l'histoire du Brésil; VIDAL. Resenha de: FONSECA, Cláudia Damasceno; OLIVEIRA. Resenha de: FONSECA. Des terres aux villes de l'or.

\section{INTRODUCÃ̃O}

1 MONTEIRO. Os concelhos e as comunidades, p. 304.

2 Sobre a organizacào politico-territorial de Portugal durante o Antigo Regime, consultar: HESPANHA. As téspenas do Leviatban; HESPANHA; SILVA. O quadro espacial.

3 BICALHO. As câmaras ultramarinas e o governo do império. Ver, também: MONTEIRO. Elites locais e mobilidade social em Portugal nos finais do Antigo Regime.

4 Para uma visào sintética deste léxico, ver: FONSECA. Regards sur le lexique urbain au Portugal et en Amérique Portugaise (XVII" - début du XIXe siècle).

5 MONTEIRO. A sociedade local e seus protagonistas, p. 36.

6 CASTRO. Mappa Cbronologico do Reino de Portugal e seus dominios, AZEVEDO. Vilas e cidades no Brasil colonial (ensaio de grografia urbana retrospectiva), p. 83-168.

7. SERRAO A concessào do foro de cidade em Portugal dos séculos XII à XIX; AZEVEDO. Vilas e cidades no Brasil colonial (ensaio de geografia urbana retrospectiva), p. 83-168.

8 HESPANHA. As vésperas do Letiatban, p. 102.

- HUETZ DE LEMPS-EMINE. Villes et petites villes en Nouvelle Castille à la fin du XVII" siècle et au début du XIX' siècle, p. 93-94.

* SERRio. A concessào do foro de cidade em Portugal dos séculos XII à XIX, p. 34-35. 